\title{
Uma nova antropologia. Unidade crítica e arranjo interdisciplinar na Dialética do Esclarecimento
}

\author{
Marcos Nobre \\ Professor de Filosofia na Unicamp e Coordenador \\ do Núcleo de Direito e Democracia do Cebrap \\ Inara Luisa Marin \\ Doutora em Psicanálise e Psicopatologia \\ pela Université Paris Diderot - Paris 7
}

Resumo: Entre muitos outros elementos, o diagnóstico de tempo que subjaz à Dialética do esclarecimento apontava para uma perda da centralidade da Economia Política no arranjo interdisciplinar da Teoria Crítica, o que exigiu uma renovação do próprio conceito de crítica. Sob esse aspecto, a principal consequência foi a emergência de uma antropologia peculiar - entendida como transformação de elementos psicanalíticos em termos de teoria social -, colocada na base de uma nova concepção de interdisciplinaridade. Em um único artigo, não é certamente possível reconstruir esse modelo crítico, mesmo em suas linhas mais gerais, mas é pelo menos possível delinear alguns de seus elementos principais e suas relações tanto com o novo arranjo interdisciplinar e com uma nova concepção de crítica.

Palavras-chave: Teoria Crítica; Dialética do esclarecimento; interdisciplinaridade; crítica; Freud; antropologia.
Abstract: Among many other elements, the diagnosis of time underlying the Dialectic of Enlightenment pointed to the lost of centrality of political economy in the interdisciplinary arrangement of Critical Theory, implying also the need for a new basis for critique itself. Under this aspect the main consequence was the emergence of a peculiar anthropology - understood in terms of a transformation of psychoanalytical elements into a social theory - that was put on the basis of a new conception of interdisciplinarity. In a single paper it is certainly not possible to reconstruct this new critical model even in its most general features, but it is at least possible to advance some of its main elements and stress their relation both to the new interdisciplinary arrangement and to the new conception of critique.

Keywords: Critical Theory; Dialect of Enlightenment; interdisciplinarity; critique; Freud; anthropology. 
É provável que o maior desconforto na leitura da Dialética do esclarecimento esteja no chocante contraste entre a organização rasgadamente ensaística do livro e o caráter universalmente peremptório de suas teses. O livro abriga formas estilísticas muito diversas: uma exposição geral seguida de dois "excursos", dois "estudos de caso" (indústria cultural e antissemitismo) e uma série de "notas e esboços". Não se trata de um conjunto de textos redutíveis a uma organização segundo "capítulos", mas, de outra parte, tampouco se pode compreender o volume como uma coleção de ensaios dispersos, enfeixados segundo um fio condutor mais ou menos arbitrário. Ao mesmo tempo, o próprio subtítulo do livro (Fragmentos filosóficos) já alerta para o equívoco de se pretender encontrar uma organização sistemática acabada de seus desenvolvimentos teóricos ${ }^{1}$.

Mas, além desse, há ainda um outro desconforto, que consiste na utilização de pensadores e obras não apenas díspares, mas inconciliáveis entre si. Acresce que essa utilização também não obedece a qualquer critério de coerência interna das obras utilizadas: Horkheimer e Adorno retiram ideias e conceitos de seus respectivos contextos e os utilizam segundo os interesses de sua própria argumentação. É possível que esse segundo desconforto possa servir melhor como fio condutor para examinar com maior profundidade o problema da unidade crítica da Dialética do esclarecimento. E sua elucidação pode bem explicar em grande medida o desconforto - digamos - estilístico do livro.

É nesse sentido que se coloca aqui inicialmente o problema da unidade crítica da Dialética do esclarecimento. Afinal, qual seria a chave

1. Assim como o próprio "Prefácio", que enuncia: "Embora tivéssemos observado há muitos anos que, na atividade científica moderna, o preço das grandes invenções é a ruína progressiva da cultura teórica, acreditávamos de qualquer modo que podíamos nos dedicar a ela na medida em que fosse possível limitar nosso desempenho à crítica ou ao desenvolvimento de temáticas especializadas. Nosso desempenho deveria restringir-se, pelo menos tematicamente, às disciplinas tradicionais: à sociologia, à psicologia e à teoria do conhecimento. Os fragmentos que aqui reunimos mostram, contudo, que tivemos de abandonar aquela confiança", ADORNO, T. W./HORKHEIMER, M. Dialética do Esclarecimento. Rio de Janeiro: Jorge Zahar Editor, 1986. p. 11, doravante abreviado DE. HORKHEIMER, M. Gesammelte Schriften, vol. 5. Frankfurt/Main: Fischer, 1987, p. 16. Doravante abreviado DA. Sobre esse ponto, ver também NOBRE, M. Lukács e os limites da reificação. Um estudo sobre História e consciência de classe. São Paulo: Editora 34, 2001, especialmente as "Considerações Finais". 
teórica que permitiria compatibilizar referências tão díspares? Qual chave permitiria entender a organização e a estruturação peculiares desse livro? Pois é patente que se encontram repetidas ao longo do livro teses e linhas de argumentação extremamente fortes e exigentes. Responder a essas perguntas parece exigir, por sua vez, que se enfrente pelo menos os seguintes problemas. Em primeiro lugar: que tipo de consequências tem a Dialética do Esclarecimento para a ideia de materialismo interdisciplinar formulada por Horkheimer nos seus escritos dos anos 1930? Ou, formulado de maneira ainda mais geral: existe uma lógica de arranjos disciplinares que decorra diretamente da proposta interdisciplinar que caracteriza e distingue a Teoria Crítica de outras formulações? Em segundo lugar: que tipo específico de fundamentação da crítica se encontra presente na Dialética do Esclarecimento? Pretende-se aqui não mais do que formular de maneira rigorosa uma hipótese de leitura que, devidamente desenvolvida, seria capaz de dar conta dessas perguntas.

São perguntas que pressupõem haver uma fundamentação para a crítica na Dialética do Esclarecimento, ao contrário da mera ideia de que não é possível fundamentar um modelo de crítica apresentado explicitamente como aporético por Horkheimer e por Adorno. A formulação mesma das perguntas acima pressupõe que há uma relação íntima entre esse modelo de crítica e a própria constelação de disciplinas que caracteriza a obra. Isso implica também dizer que, do ponto de vista da constelação de disciplinas presente no ensaio seminal "Teoria Tradicional e Teoria Crítica", o modelo crítico² da Dialética do Esclarecimento não é, de fato, passível de fundamentação.

Mas, se se pensa a Dialética do Esclarecimento no contexto de um rearranjo interdisciplinar, torna-se possível pensar esse livro como um novo modelo crítico. Isso significa, de um lado, que continua a ser possível entendê-lo (e mesmo criticá-lo) a partir do modelo presente em "Teoria Tradicional e Teoria Crítica". De outro lado, entretanto, há especificidades e potenciais críticos nesse novo modelo que se perdem se ele for medido sem mais pelo gabarito de "Teoria Tradicional e Teoria Crítica". Pois é possível caracterizar um modelo crítico por pelo menos três marcas distintivas, segundo: a forma com que se

2. Sobre a ideia de "modelo crítico", ver NOBRE, M. A Teoria Crítica. Rio de Janeiro: Jorge Zahar Editor, 2004, e ainda NOBRE, M (org.). Curso Livre de Teoria Crítica. Campinas: Papirus, 2008. 
relaciona com a Teoria Tradicional ${ }_{\text {; }}$ a configuração disciplinar a partir da qual se organiza; a necessidade ou não de realizar investigações empíricas próprias ${ }^{3}$. No caso dos escritos de Horkheimer da década de 1930 ,

fica evidente que a crítica da economia política ocupa o centro da constelação disciplinar. O que corresponde ao diagnóstico do tempo segundo o qual o mercado continuava a ser a instituição social estruturante, mesmo se o próprio capitalismo já tinha passado a uma fase monopolista. Nesse contexto, é o conceito de "classe" (com todas as suas obscuridades - e elas são muitas, com certeza - nos escritos de Horkheimer desse período) que permite a passagem entre a crítica da economia política como foco e núcleo do arranjo disciplinar a investigações empíricas, como aquela dirigida por Erich Fromm sobre o autoritarismo nas famílias proletárias, por exemplo ${ }^{4}$.

Pretende-se mostrar aqui que a Dialética do esclarecimento introduz um novo modelo crítico também porque foi produzida em vista de um novo arranjo interdisciplinar, solidário de um novo diagnóstico do tempo presente. E essa nova configuração não apenas coloca a psicanálise no centro da constelação disciplinar, como se bastasse colocar no lugar da "economia política" uma leitura interessada de Freud. Trata-se de uma outra maneira de fazer convergir as diferentes disciplinas, trata-se de um modelo que projeta uma nova relação entre as disciplinas, em que o peculiar "materialismo psicanalítico" do livro deveria como que fornecer um "campo comum" para o debate e a investigação interdisciplinar. Que esse modelo não tenha tido continuidade em termos de investigações coletivas por parte do Instituto de Pesquisa não diminui em nada sua importância e relevância para sua eventual atualização. É flagrante o contraste, entretanto, entre, de um lado, as muitas e influentes atualizações do modelo crítico da Dialética do esclarecimento, e, de outro lado, o silêncio sobre o modelo de investigação interdisciplinar que projeta.

Seja como for, é necessário estabelecer de saída que os problemas tais como formulados aqui dizem muito mais diretamente res-

3. Ver NOBRE, M. e REPA, L. (orgs.). Habermas e a reconstrução. Sobre a categoria central da Teoria Crítica habermasiana. Campinas: Papirus, 2012, pp. 13-17.

4. Idem, p. 16. 
peito ao desenvolvimento teórico de Hokheimer do que ao de Adorno. Ou seja, opera aqui o pressuposto de que Horkheimer tem primazia nesse processo de colaboração que resultou na coautoria do livro. Nesse sentido, seria possível encontrar nos escritos de Horkheimer dos anos 1930 dois projetos distintos e, por vezes, conflitantes. Um deles é justamente aquele que culmina no ensaio "Teoria Tradicional e Teoria Crítica", de 1937. O outro diz respeito ao projeto de uma "antropologia da época burguesa", expressão utilizada por Horkheimer no subtítulo do ensaio "Egoísmo e movimento de libertação", de 1936. Vista dessa maneira, a Dialética do Esclarecimento significaria, de um lado, uma ruptura com o projeto presente no texto de 1937. Mas, ao mesmo tempo, como tentaremos mostrar, daria continuidade a certos motivos e desenvolvimentos teóricos que já estavam presentes no ensaio de $1936^{5}$.

Se é verdade que a ruptura da Dialética do Esclarecimento foi, em grande medida, influenciada pelo diagnóstico geral de Friedrich Pollock do "capitalismo de Estado", nem por isso Horkheimer e Adorno aceitaram sem mais as formulações derivadas dessa nova situação história. Apesar de concordarem, de maneira geral, com a ideia de Pollock de uma nova forma de "primazia da política" sobre a economia em condições nãosocialistas, na Dialética do Esclarecimento o que encontramos não é a adesão a uma das "formas" do "capitalismo de Estado" tais como formuladas teoricamente por Pollock (a "forma autoritária" e a "forma democrática"), mas antes uma variante da "forma autoritária" que Horkheimer e Adorno denominaram "mundo administrado".

Mesmo considerando que a economia política não deveria mais ser tomada como a disciplina central no arranjo interdisciplinar da Teoria Crítica, Horkheimer e Adorno não se dedicaram a formular de maneira direta uma teoria política crítica, como seria de se esperar a

5. Sobre este e outros aspectos, consulta-se a notável biografia intelectual realizada por ABROMEIT, J. Max Horkheimer and the foundations of the Frankfurt School. Cambridge: Cambrige UP, 2011.

6. Sobre isso, ver NOBRE, M. A dialética negativa de Theodor W. Adorno. A ontologia do estado falso. São Paulo: Iluminuras/FAPESP, 1998, especialmente o capítulo 1. Nessa constelação, o ensaio de Horkheimer "Estado autoritário" (1942) ocupa uma posição central. Assim como o ensaio "Razão e autopreservação" (1940/1942) pode ser visto como em continuidade com o projeto presente em "Egoísmo e movimento de libertação". 
partir da mudança de diagnóstico do tempo realizada a partir dos trabalhos de Pollock. A tese defendida aqui, ao contrário, é a de que foi uma peculiar antropologia, entendida em termos de uma transformação da psicanálise freudiana tornada teoria social, que reformulou a ideia mesma de interdisciplinaridade tal como pensada até então.

A ideia é a de que a perda de centralidade da economia no arranjo disciplinar dos anos 1940 implicou também um novo problema de fundamentação para a própria crítica. Como escreveram Horkheimer e Adorno no "Prefácio" ao livro,

A aporia com que defrontamos em nosso trabalho revela-se assim como o primeiro objeto a investigar: a autodestruição do esclarecimento. Não alimentamos dúvida nenhuma - e nisso reside nossa petitio principii - de que a liberdade na sociedade é inseparável do pensamento esclarecedor. Contudo, acreditamos ter reconhecido com a mesma clareza que o próprio conceito desse pensamento, tanto quanto as formas históricas concretas, as instituições da sociedade com as quais está entrelaçado, contém o germe para a regressão que hoje tem lugar em toda parte. Se o esclarecimento não acolhe dentro de si a reflexão sobre esse elemento regressivo, ele está selando seu próprio destino 7 .

Segundo a hipótese enunciada aqui, a correta compreensão da estrutura dessa aporia e sua específica fundamentação crítica têm de ser buscadas em uma nova antropologia, entendida como uma versão transformada de teses freudianas ${ }^{8}$. Mas isso significa também que essa nova antropologia borra inteiramente as fronteiras entre as disciplinas tais como entendidas até os anos 1930. Pois essa nova antropologia não pode ser reduzida a nenhuma disciplina existente. Não se pode dizer dela que seja uma nova disciplina, a ser colocada no centro de um novo arranjo interdisciplinar, no papel antes ocupado pela Economia Política. É a ideia mesma de interdisciplinaridade que está em questão na Dialética do Esclarecimento.

Tampouco se pode dizer, entretanto, que a ideia de colaboração entre as disciplinas tenha desaparecido. $\mathrm{O}$ que desapareceu foi a cen-

7. DE, p. 13 ; DA, pp. 18-19

8. Ver a esse respeito, MARIN, I. L. Psychanalyse et Théorie Critique. Tese de Doutorado, Université de Paris VII, 2009. Muitos dos argumentos e formulações utilizadas aqui provêm desse trabalho. 
tralidade da Economia Política. De outro lado, Horkheimer e Adorno como que criaram, com isso que é chamado aqui de nova antropologia, um ambiente, um espaço de diálogo interdisciplinar novo. De certa maneira, é para o fulcro desse novo ambiente interdisciplinar que pretende apontar a exposição que se segue. Mas não sem antes esclarecer o ponto de vista a partir do qual foi escrito este texto. O pressuposto aqui é o de que o modelo crítico apresentado na Dialética do Esclarecimento, com seu diagnóstico do tempo e seus específicos prognósticos, mostrou-se equivocado em vários sentidos e que não serve para compreender o momento atual em toda a sua complexidade. Entretanto, duas observações em sentido contrário se fazem necessárias.

Em primeiro lugar, para poder levar a Teoria Crítica para além da Dialética do Esclarecimento, mas com ela, é preciso realizar a devida avaliação do modelo crítico que representa, tarefa que não nos parece ter sido realizada em sua plenitude até hoje. Daí a proposta de buscar na específica versão da psicanálise freudiana em termos de filosofia social, em termos de uma nova antropologia, o cerne desse modelo crítico. É bem possível que esse ponto central tenha ficado obscurecido em razão dos posicionamentos sectários que o livro provocou, seja a favor, seja contra ele. Em segundo lugar, parece óbvio que há ainda muito por preservar desse livro de 1947. Para mencionar apenas dois exemplos clássicos, pode ser que tenham aparecido explicações tão abrangentes e tão fecundas sobre os fenômenos da indústria cultural e do nazismo desde então, mas não interpretações que superem ou dispensem as análises da Dialética do Esclarecimento. Se há certamente que modificar nossa compreensão desses dois fenômenos em vista da situação atual, esse livro continua a ser o ponto de partida necessário para fazê-lo.

$\mathrm{O}$ argumento aqui é que Horkheimer e Adorno conseguiram formular explicações tão instigantes sobre fenômenos como os da indústria cultural e do nazismo exatamente porque formularam um novo tipo de antropologia, que alterou profundamente os termos do arranjo interdisciplinar que caracterizou a Teoria Crítica nos anos 1930. Na nova formulação da Dialética do Esclarecimento, a psicologia social pensada em termos antropológicos nos alerta também para o fato de que a psicanálise e a psicologia social de maneira mais ampla já permaneceram tempo demais marginalizadas no campo crítico, desde pelo menos a década de 1970. É mais que tempo de dar à psicanálise e à psicologia social a posição de destaque que lhes deveria caber nos arranjos interdisciplinares atuais. Para isso, entretanto, é preciso que surjam teóricos críticos que se dediquem a essa tarefa, 
lacuna que talvez só não seja mais grave do que o déficit de teóricos críticos no campo da economia.

É recomendável que se comece pelas principais e mais conhecidas das teses da Dialética do Esclarecimento. Já no "Prefácio", referindo-se à exposição geral com que iniciam o livro e que tem o título de "Conceito de esclarecimento", Horkheimer e Adorno escrevem: "Em linhas gerais, o primeiro estudo pode ser reduzido em sua parte crítica a duas teses: o mito já é esclarecimento e o esclarecimento acaba por reverter à mitologia"9.

Com respeito à segunda das duas teses (a recaída do esclarecimento no mito), a elucidação veio já apresentada um pouco antes no mesmo "Prefácio":

a causa da recaída do esclarecimento na mitologia não deve ser buscada tanto nas mitologias nacionalistas, pagãs e em outras mitologias modernas especificamente idealizadas em vista dessa recaída, mas no próprio esclarecimento paralisado pelo temor (Furcht) da verdade. Neste respeito, os dois conceitos [mito e esclarecimento] devem ser compreendidos não apenas como histórico-culturais, mas como reais $(\text { real })^{10}$.

E a primeira tese (a do mito já ser esclarecimento), por sua vez, aparece elucidada logo na abertura do "primeiro estudo":

No sentido mais amplo do progresso do pensamento, o esclarecimento tem perseguido sempre o objetivo de livrar os homens do medo (Furcht) e de investi-los na posição de senhores. Mas a terra totalmente esclarecida resplandece sob o signo de uma calamidade triunfal. O programa do esclarecimento era o desencantamento do mundo ${ }^{11}$.

A hipótese defendida aqui é a de que essa presença do "medo" e do "temor" é de fundamental importância na apresentação e elucidação das duas teses fundamentais do primeiro estudo. Para isso, começamos por ressaltar que a tradução brasileira, apesar de ser de alta qualidade, traduziu a mesma palavra (Furcht) diferentemente nos dois trechos citados. E que esse problema se agrava quando se examina o conceito inseparável com

\footnotetext{
9. DE, p. 15 ; DA, p. 21.

10. DE, p. 13; DA, p. 19.

11. DE, p. $19 ;$ DA, p. 25.
} 
que "Furcht" (que traduziremos por "medo") faz par na Dialética do Esclarecimento, a noção de "Angst" (que traduziremos por "angústia"). É esse par conceitual que pretendemos examinar mais detidamente. O que levará também às noções de "Mimesis" (que traduziremos por "mimese") e de "Schrecken" (que traduziremos por "terror"), igualmente pertencentes à constelação conceitual de que nos ocuparemos aqui ${ }^{12}$.

Se bem compreendida em sua posição na argumentação do livro, a constelação que envolve os termos "Schrecken", "Furcht", "Angst", "Mimesis" e, além deles, também o de "Gefahr" ("perigo"), pode servir de base a uma tentativa de entender a unidade crítica da Dialética do Esclarecimento como um todo. Uma hipótese formulada de tal maneira que sua ambição explicativa pretende abarcar até mesmo o princípio estilístico de construção do livro: com suas construções chocantes (no sentido dos ensaios de Benjamin sobre Baudelaire $\left.{ }^{13}\right)$, elípticas e peremptórias, Horkheimer e Adorno mimetizariam o medo que fez do mito esclarecimento e do esclarecimento mito ${ }^{14}$.

Essa hipótese de conjunto encontra apoio inicialmente na passagem do "Prefácio" de 1944, em que Horkheimer e Adorno caracterizam da seguinte maneira a última parte da Dialética do Esclarecimento, intitulada "Fragmentos e esboços":

$\mathrm{Na}$ última parte publicam-se notas e esboços que, em parte, pertencem ao horizonte intelectual dos estudos precedentes, sem encontrar aí seu lugar, e em parte traçam um esboço provisório de problemas a serem tratados num trabalho futuro. A maioria deles refere-se a uma antropologia dialética ${ }^{15}$.

12. Não trataremos aqui das possíveis aproximações e dos devidos afastamentos dessa constelação de noções com o universo hegeliano, em especial da Fenomenologia do espírito, em que essas noções desempenham papel de importância em pelo menos três momentos: na chamada dialética do senhor e do servo, no capítulo $\mathrm{IV}_{\text {; }}$ ao final do capítulo VI ("O espírito"); e ainda no último capítulo do livro ("O saber absoluto").

13. Sobre a importância do Freud de Para além do princípio do prazer tanto em Benjamin quanto na Dialética do Esclarecimento, veja-se adiante.

14. Essa hipótese pode também conferir maior densidade à afirmação tão conhecida do livro: "Só o pensamento que faz violência a si mesmo é suficientemente duro para destruir os mitos" (DE, p. 20; DA, p. 26).

15. DE, p. 17; DA, p. 23. 
Apesar da menção a um trabalho ainda por vir, fica claro que a ideia de uma "antropologia dialética" já se encontra desenvolvida, pelo menos "em parte", no livro de 1947. É nesse sentido que é possível também aproximar a Dialética do Esclarecimento não apenas de Freud, mas também do jovem Marx ${ }^{16}$ e de Rousseau ${ }^{17}$. Nesse sentido, a dialética entre comportamento mimético e auto-preservação se desenvolve de maneira a expulsar a mimese do domínio do racional na forma de uma apropriação da ideia de recalque freudiano, da "Verdrängung"118, consagrando assim a pretensão exclusivista da auto-preservação na determinação da esfera própria do racional. Seja como for, a ideia defendida aqui é a de que são teses antropológicas derivadas de Freud que permitem vislumbrar a real identidade argumentativa e crítica do livro e de que essa apropriação de Freud por Horkheimer e Adorno se dá como incorporação da arquitetônica pulsional em novos termos. Nesse caso, a própria constelação de elementos fundamentais que compõem essa apropriação é igualmente freudiana. É dessa constelação que se trata aqui.

No nível puramente natural da sua existência, a espécie encontra-se diante do "perigo absoluto" ("absolute Gefahr"). Ainda que já mediado primeiramente pelo comportamento mimético, esse perigo não pode ser evitado: ele se mostra como "terror" ("Schrecken"). Segundo o texto:

Para a civilização, a vida no estado natural puro, a vida animal e vegetativa, constituía o perigo absoluto. Um após o outro, os comportamentos mimético, mítico e metafísico foram considerados como eras superadas, de tal sorte que a ideia de recair neles estava

16. Essa aproximação pode começar a ser construída consultando-se GIANNOTTI, J. A. Origens da dialética do trabalbo. Estudo sobre a lógica do jovem Marx. Porto Alegre: L\&PM, 1985, especialmente p. 21.

17. Essa aproximação parece poder ser realizada não apenas sob o aspecto de uma "história negativa" (nos termos do Segundo Discurso), mas também mediante uma transposição em termos pulsionais freudianos dos sentimentos de "piedade natural" e de "amor de si". Sobre isso, consulte-se MARIN, I. L. Equilíbrio da natureza - equilíbrio na sociedade: configurações todo-parte na filosofia de Jean-Jacques Rousseau. Dissertação de Mestrado. São Paulo: USP, 1999.

18. "A ratio, que recalca a mimese, não é simplesmente seu contrário. Ela própria é mimese: a mimese do que está morto" (DE, p. 62; DA, p. 81). Sobre uma possível interpretação "pulsional" da mimese, ver adiante. 
associada ao terror ("Schrecken") de que o eu revertesse à mera natureza, da qual havia se alienado com esforço indizível e que por isso mesmo infundia nele indizível terror (Grauen, melhor vertido como "horror" $)^{19}$.

Seria interessante comparar essas três diferentes "eras" ("Weltalter") com os famosos três estágios de Auguste Comte ou com as formulações de Schelling. Mas isso levaria muito longe. Cabe apenas enfatizar aqui o elemento que funciona como o verdadeiro motor da dialética do esclarecimento: o terror. É o terror da regressão ao "eu meramente natural" que impele para a próxima figura, para a próxima "era", como o vento do progresso que, em Benjamin, impele o anjo da história (ele mesmo aterrorizado) irresistivelmente para o futuro.

É por essa razão que Horkheimer e Adorno escrevem, já em "Elementos do anti-semitismo":

A constelação (...) na qual a identidade se produz - a identidade imediata da mimese assim como a identidade mediatizada da síntese, a assimilação à coisa no ato cego de viver, assim como a comparação dos objetos reificados na conceitualidade científica - continua a ser a constelação do terror (Schrecken) ${ }^{20}$.

Mas se é assim, se a constelação do terror é aquela que preside a própria dialética do esclarecimento, que preside ao desenvolvimento que leva do estilingue à bomba atômica, quais são seus elementos?

É bastante conhecida a tese de Horkheimer e Adorno da automatização da auto-preservação, de tal maneira que "a dominação da natureza interna e externa tornava-se o fim absoluto da vida". Tal se dá porque o esclarecimento impõe uma alternativa inescapável, que torna inevitável a própria dominação: "Os homens sempre tiveram de escolher entre submeter-se à natureza ou submeter a natureza ao eu" ${ }^{\prime \prime 21}$.

19. DE, p. 42 ; DA, p. 54.

20. DE, p. 169; DA, p. 211.

21. O contexto mais amplo da passagem é o seguinte: "Nos momentos decisivos da civilização ocidental, da transição para a religião olímpica ao renascimento, à reforma e ao ateísmo burguês, todas as vezes que novos povos e camadas sociais recalcavam o mito, de maneira mais decidida, o temor (Furcht) da natureza não compreendida e ameaçadora - consequência da sua própria materialização e objetualização - era degradado em superstição animista, e 
A nosso ver, a dialética que está em jogo aqui - e que resulta na dupla dominação, da natureza interna e externa - começa pela angústia ("Angst") de uma natureza ameaçadora e essencialmente incompreendida. Segundo a dialética do terror, essa angústia exige uma interiorização da ameaça, uma determinação do objeto perigoso, de modo a buscar sempre a sua neutralização. Essa relativa estabilização alcançada nos sucessivos estágios ou eras ("mimético, mítico e metafísico") surge como medo ("Furcht").

O medo indica que as sucessivas tentativas de interiorização da natureza ameaçadora sempre deixam restos. As tentativas de neutralizar a ameaça angustiante não podem nunca afastá-la inteiramente. Não há como interiorizar sem resto a natureza externa e suas ameaças. Essa impossibilidade, com suas cicatrizes, marcas e feridas que nunca se fecham completamente, esses rastros dolorosos da dialética do terror é o que Horkheimer e Adorno chamam de medo.

Daí a reunião em uma única passagem (ainda que longa) dos elementos da constelação em causa:

O conceito, que se costuma definir como a unidade característica do que está nele subsumido, já era desde o início o produto do pensamento dialético, no qual cada coisa só é o que ela é tornando-se aquilo que ela não é. Eis aí a forma primitiva da determinação objetivadora na qual se separavam o conceito e a coisa, determinação essa que já está amplamente desenvolvida na epopéia homérica e que se acelera na ciência positiva moderna. Mas essa dialética permanece impotente na medida em que se desenvolve a partir do chamado do terror (Ruf des Schreckens), que é a própria duplicação, a tautologia do terror (Schrecken). Os deuses não podem livrar os homens do medo (Furcht), pois são as vozes petrificadas do medo (Furcht) que eles trazem como nome. Do medo (Furcht) o homem presume estar livre quando não há nada mais de desconhecido. É isso que determina o trajeto da desmitologização e do esclarecimento, que identifica o animado ao inanimado, assim como o mito

a dominação da natureza interna e externa tornava-se o fim absoluto da vida. Quando afinal a autoconservação se automatiza, a razão é abandonada por aqueles que assumiram sua herança a título de organizadores da produção e agora a temem nos deserdados. A essência do esclarecimento é a alternativa cuja inevitabilidade é a da dominação. Os homens sempre tiveram de escolher entre submeter-se à natureza ou submeter a natureza ao eu"( DE, p. 43; DA, p. 55). 
identifica o inanimado ao animado. $\mathrm{O}$ esclarecimento é a angústia (Angst) tornada radical, mítica. A pura imanência do positivismo, seu derradeiro produto, nada mais é do que um tabu, por assim dizer, universal. Nada mais pode ficar de fora, porque a simples ideia do 'fora' é a verdadeira fonte da angústia ${ }^{22}$.

Dito de outra maneira ainda: sendo o "padrão" da relação homem/ natureza no "estado de natureza" a mimese, a passagem ao "estado de sociedade" é a instauração do medo, que, desse modo, não é apenas modelo de relação do homem com a natureza, mas modelo social da relação homem/homem. É o que encontramos na abertura do livro, que vale a pena citar ainda uma vez: "No sentido mais amplo do progresso do pensamento, o esclarecimento tem perseguido sempre o objetivo de livrar os homens do medo e de investi-los na posição de senhores. Mas a terra totalmente esclarecida resplandece sob o signo de uma calamidade triunfal"23.

Habermas foi ao ponto quando escreveu: "Dado que o comportamento mimético, 'o amoldar-se orgânico ao outro', permanece sob o signo do medo, a mimese não assume o papel de guardadora de lugar para uma razão originária, cujo posto foi usurpado pela razão instrumental ${ }^{1 / 24}$. O que nos parece não se seguir é a consideração de Habermas segundo a qual o exercício mesmo da crítica na Dialética do Esclarecimento se encontra minado em sua base. Segundo ele, "Horkheimer e Adorno (...) intensificam e mantêm aberta a contradição performativa de uma crítica da ideologia que suplanta a si mesma, sem querer superá-la teoricamente ${ }^{125}$. Para suplantar essa aporia que não se fecha e que não tem perspectiva de ser superada, Habermas pretende encontrar na mimese de Horkheimer e Adorno as pistas para um conceito alternativo de razão que não esteja bloqueado pela dialética do esclarecimento.

22. DE, p. 29; DA, p. 38.

23. DE, p. 19; DA, p. 25.

24. HABERMAS, J. Theorie des kommunikativen Handelns, vol. 1. Frankfurt/Main, 1987, p. 512.

25. HABERMAS, J. O Discurso Filosófico da Modernidade. São Paulo: Martins Fontes, 2000, pp. 182-183. Der philosopbische Diskurs der Moderne. Frankfurt/Main: Suhrkamp, 1985, p. 154. 
Dizendo de maneira breve: Habermas tem toda razão em fazer uma crítica como essa do ponto de vista do ensaio "Teoria Tradicional e Teoria Crítica". Do ponto de vista desse escrito de 1937, parece realmente que não há como defender o modelo de crítica da Dialética do Esclarecimento. Se, porém, esse novo modelo for olhado do ponto de vista de uma "nova antropologia", que pretende criar o ambiente interdisciplinar necessário ao diálogo entre as especialidades, não há sentido em falar em uma "razão originária", nem de imaginar sucedâneos e "guardadores de lugar". E, no entanto, uma tal interpretação alternativa só se torna possível, a nosso ver, se indicar o papel central que desempenham os elementos freudianos na construção desse novo modelo crítico.

Foi possível tomar aqui como fio condutor a constelação do "terror", porque todos os seus termos são freudianos e se beneficiam da unidade dos escritos da década de 1920. Foi Freud quem primeiro distinguiu conceitualmente todos os termos dessa constelação em Para Além do Princípio do Prazer (1920). A referência a este livro não é de modo algum casual aqui. Para dar apenas um exemplo, recorremos a um conjunto de notas de Adorno, do ano de 1941, que têm por título "Notizen zur neuen Anthropologie" e, mais especificamente, à seguinte passagem:

Freud se representa os processos pulsionais como uma espécie de troca de equivalentes. Entretanto, os esquemas de troca da pulsão, colocados por Freud, não mais são válidos tão logo o Eu não dispõe mais de poder sobre a massa pulsional que lhe está subordinada. Quando se formam sujeitos coletivos, toda a economia pulsional é posta fora de ação juntamente com o mecanismo do prazer. Em seus trabalhos mais avançados, sobretudo em Para além do princípio do prazer, Freud viu algo disso, mas não tirou as consequências ${ }^{26}$.

26. ADORNO, T. W./HORKHEIMER, M. Briefwechsel. vol. II: 1938-1944. Frankfurt/Main: Suhrkamp, 2004, p. 454. Também não é por acaso, certamente, que Para além do princípio do prazer seja o texto freudiano de referência para os desenvolvimentos de Benjamin na terceira parte de seu ensaio "Sobre alguns motivos em Baudelaire" In: Gesammelte Scbriften. vol. I.2. Frankfurt/Main: Suhrkamp, 1972, pp. 612 e ss.. Além disso, é ainda de capital importância lembrar aqui a observação do Vocabulaire de la Psychanalyse, de Jean Laplanche e J.-B. Pontalis (Paris: PUF, 1992, p. 129), segundo a qual pode-se dizer "que no conjunto o significado do termo effroi (temor) não variou em Freud. Note-se apenas que, depois de Para além do princípio de prazer, 
Freud apresenta sucintamente os termos da seguinte maneira:

Terror (Schreck), temor (Furcht), angústia (Angst) são empregados equivocadamente como expressões sinônimas; elas se deixam distinguir bem em sua relação com o perigo (Gefahr). A angústia designa um certo estado, como a expectativa do perigo e a preparação para o mesmo, mesmo que ele seja um perigo desconhecido ${ }_{i}$ o medo exige um objeto determinado, diante do qual ficamos amedrontados; terror, no entanto, designa o estado em que nos encontramos quando estamos em perigo sem termos nos preparado para ele, enfatiza o momento da surpresa ${ }^{27}$.

Não pretendemos afirmar que Freud tenha utilizado esses termos ao longo de sua obra segundo essas precisões conceituais que ele próprio estabeleceu, nem que seu emprego seja sempre uniforme. Mas, sob esse aspecto, também Horkheimer e Adorno não utilizaram esses termos em sentido rigoroso estrito ${ }^{28}$. Não pretendemos igualmente

o termo tende a ser menos empregado. A oposição que Freud havia tentado estabelecer entre os dois termos de angústia e de temor vai se dar, mas sob a forma de diferenciações no interior da noção de angústia, notadamente na oposição entre uma angústia que sobrevém 'automaticamente' em uma situação traumática, e o sinal de angústia que implica uma atitude de espera ativa (Erwartung) e protege contra o desenvolvimento da angústia". Traduzido nos termos da interpretação proposta aqui, Horkheimer e Adorno se apoiam antes no Freud de Para além do princípio do prazer do que nos escritos posteriores para construir a específica "constelação do terror", que, acreditamos, caracteriza mais amplamente a Dialética do Esclarecimento.

27. FREUD, S. Gesammelte Werke. Vol. XIII. Frankfurt/Main: Fischer, 1999, p. 10. Na apresentação de "Inibição, sintoma e angústia" (1926): "A angústia (Angst) possui uma relação ineludível com a expectativa; ela é angústia diante (vor) de algo. É-lhe inextrincável um caráter de indeterminidade (Unbestimmtheit) e de carência de objetidade (Objektlosigkeit); quando ela encontrou um objeto, o correto uso lingüístico altera seu nome e o substitui então por medo (Furcht)" (Vol. XIV, pp. 197-198).

28. Além disso, o quadro não fica completo sem o conceito de recalque, central tanto para a teoria freudiana como para a releitura de Horkheimer e Adorno. Freud, em um primeiro momento, estabelece o recalque como causa da angústia, enquanto, em um segundo momento (a partir de 1926, com "Inibição, sintoma e angústia" justamente), estabelece a angústia como causa do recalque. Não pensamos, entretanto, que essa dificuldade sistemática tenha se posto enquanto tal para a leitura de Freud por Horkheimer e Adorno, que é 
dizer que, com essa mera referência, ficam resolvidos problemas tão fundamentais quanto os da passagem da angústia ao sujeito da angústia $^{29}$, ou ainda o da pulsão como afeto, ou mesmo a passagem entre angústia e pulsão (que remete, uma vez mais, ao problema da identificação). Muito menos as dificuldades em compreender a versão específica que deram Horkheimer e Adorno desses problemas sob forma de uma filosofia da história a contrapelo e de uma peculiar antropologia. Mas pretendemos afirmar que são esses os termos do problema e é deles que acreditamos que se deva partir para reconstruir a unidade crítica da Dialética do Esclarecimento.

nosso objeto aqui. Uma maneira de figurar a hipótese de leitura da apropriação da teoria freudiana por Horkheimer e Adorno que apresentamos aqui é a de imaginar que, na Dialética do Esclarecimento, a formulação dos conceitos pertence ao universo de "Inibição, sintoma e angústia", mas o sentido que recebem depende do quadro teórico de Para além do princípio do prazer.

29. A liquidação tendencial do indivíduo faz parte do diagnóstico do tempo mais geral da Dialética do Esclarecimento. Para ficar em um único exemplo entre muitos: "O individual se reduz à capacidade do universal de marcar tão integralmente (ohne Rest) o contingente que ele possa ser conservado como o mesmo [...]. A pseudo-individualidade é um pressuposto para compreender e tirar da tragédia sua virulência: é só porque os indivíduos não são mais indivíduos, mas sim meras encruzilhadas das tendências do universal, que é possível reintegra-los sem falha (bruchlos) na universalidade" (DE, 144-145; DA, pp. 181-182). Uma das consequências importantes desse diagnóstico para a transfiguração do esquema conceitual freudiano por Horkheimer e Adorno está, por exemplo, no conceito mesmo de narcisismo e sua relação com o Eu. Em carta a Horkheimer de $1^{\circ}$. de janeiro de 1945, Adorno escreveu o seguinte: "Estamos com certeza de acordo em que, com a dissolução do Eu, também não pode mais haver nenhum narcisismo do velho estilo. $\mathrm{O}$ que está diante de nós exatamente é provavelmente antes um mecanismo de identificação imediata do Eu desprovido de Si (entselbsteten) com a instância coletiva e a função da psicologia popular é essencialmente a promoção de um tal desempenho mecânico e peculiarmente externo. Trata-se ao mesmo tempo da herança do narcisismo, semelhante a como o monopólio recebeu a herança do capitalismo privado. Ou antes: em lugar de cada qual satisfazer seu narcisismo como uma forma de propriedade privada, ele recebe o quantum de prazer desse tipo que lhe cabe, o qual, entretanto, de há muito já não é o do Eu no sentido autêntico, atribuído imediatamente pelo 'aparato de distribuição' psicológico" (ADORNO, T. W./HORKHEIMER, M. Briefwechsel. Vol. II, p. 420). Sobre isso, ver MARIN, I. L. Psychanalyse et Théorie Critique. Tese de Doutorado. 
Para analisar com um pouco mais de detalhe apenas uma dessas diferenças, vale lembrar a passagem de "Inibição, sintoma e angústia", em que Freud distingue a "angústia real" da "angústia neurótica" e relaciona esta última com um perigo pulsional (o que, mais uma vez, mostra afinidade com as teses fundamentais da Dialética do Esclarecimento):

O perigo real é aquele que conhecemos, a angústia real aquela que se dá diante de um tal perigo conhecido. A angústia neurótica é angústia diante de um perigo que não conhecemos. É preciso, portanto, buscar primeiramente o perigo neurótico $;$ a análise nos ensinou que ele é um perigo pulsional. Na medida em que trazemos à consciência esse perigo desconhecido para o eu, borramos a diferença entre angústia real e angústia neurótica, podemos tratar tanto a primeira quanto a segunda ${ }^{30}$.

Para Horkheimer e Adorno, a dificuldade está em que esse "trazer à consciência" da angústia primordial encontra-se objetivamente bloqueado por uma organização social em que o recalque é já segunda natureza e é elevado à lógica mesma de funcionamento de uma dominação sem fissuras: "O esclarecimento é a angústia (Angst) tornada radical, mítica"31.

Apesar de reconhecer todas essas diferenças e divergências, não vemos como encontrar a unidade crítica da Dialética do Esclarecimento em outro lugar que não em uma apropriação crítica peculiar da teoria freudiana por Horkheimer e Adorno em termos de uma nova antropologia. Essa hipótese parece permitir compreender também outros elementos importantes (e, não por acaso, simétricos), como a apropriação do processo de racionalização weberiano, sem sua concepção multidimensional da racionalidade, ou mesmo a apropriação do conceito lukácsiano de reificação, sem a correspondente aceitação de sua limitação histórica ao capitalismo e da noção de totalidade capaz de explicá-1o ${ }^{32}$.

30. FREUD, S. Gesammelte Werke. Vol. XIV. Frankfurt/Main: Fischer, 1999, p. 198.

31. "Aufklärung ist die radikal gewordene, mythische Angst" (DE, p. 29; DA, p. 38).

32. Apenas para ressaltar uma das muitas consequências perturbadoras dessa maneira de reconstruir a Dialética do Esclarecimento: se a formulação dos problemas se dá fundamentalmente a partir de uma apropriação antropológico-materialista de Freud, também as muitas apropriações de teses e formulações de Weber e de Lukács no livro são realizadas a partir desse enquadramento essencialmente freudiano. E não o contrário. 
Segundo nossa hipótese, o modelo crítico de Dialética do esclarecimento distingue-se igualmente do modelo crítico do jovem Marx, embora ambos tenham feições antropológicas. Como é possível constatar, por exemplo, na seguinte passagem do livro:

Inicialmente, em sua fase mágica, a civilização havia substituído o amoldar-se orgânico ao outro, isto é, o comportamento propriamente mimético, pela manipulação organizada da mimese e, por fim, na fase histórica, pela práxis racional, isto é, pelo trabalho. A mimese incontrolada é proscrita ${ }^{33}$.

Fica claro aqui que, ao contrário do jovem Marx, Horkheimer e Adorno recuam para um momento anterior ao trabalho, a partir do qual o momento do trabalho já surge, ele próprio, como reificado.

Além disso, é a partir dessa nova unidade crítica dada por uma antropologia obtida a partir de formulações freudianas que o fascismo poderá se mostrar como aquela mesma "mimese de morte" característica do recalque da mimese pela ratio. Como, por exemplo, na seguinte passagem:

O sentido das fórmulas fascistas, da disciplina ritual, dos uniformes e de todo o aparato pretensamente irracional é possibilitar o comportamento mimético. Os símbolos engenhosamente arquitetados, próprios a todo movimento contra-revolucionário, as caveiras e mascaradas, o bárbaro rufar dos tambores, a monótona repetição de palavras e gestos são outras tantas imitações organizadas de práticas mágicas, mimese da mimese ${ }^{34}$.

O mesmo traço, aliás, que se pode encontrar em relação às análises da indústria cultural. Como, por exemplo:

As mais íntimas reações das pessoas estão tão completamente reificadas para elas próprias que a idéia de algo peculiar a elas só perdura na mais extrema abstração: personality significa para elas pouco mais do que possuir dentes deslumbrantemente brancos e estar livres do suor nas axilas e das emoções. Eis aí o triunfo da publicidade na indústria cultural, a mimese compulsiva dos consumidores com as

\footnotetext{
33. DE, p. 168.

34. DE, p. 172
} 
mercadorias culturais que eles, ao mesmo tempo, decifram muito bem $^{35}$.

Para além dos exemplos, pretendemos que a hipótese sistemática formulada permita compreender com maior rigor a própria concepção de racionalidade que subjaz ao esforço de Horkheimer e de Adorno. $\mathrm{O}$ jogo bruto das pulsões freudianas ${ }^{36}$ é interpretado por eles em termos sócio-históricos como inevitabilidade da dominação: "A essência do esclarecimento é a alternativa que torna inevitável a dominação ${ }^{\prime \prime 3}$. Daí também que a razão não seja algo destacado da mimese, tampouco o seu contrário: a razão é, no jogo bruto das pulsões, a imposição sem contestações da "mimese de morte" por sobre a "mimese de vida". É nesse sentido que Horkheimer e Adorno afirmam que a "ratio, que recalca a mimese, não é simplesmente seu contrário. Ela própria é mimese: a mimese do que está morto"${ }^{138}$. E essa mimese do que está morto é exatamente, para Horkheimer e Adorno, a produção da igualdade universal do conceito e da troca.

Nesse momento, parece já adequado retomar a releitura daquela passagem com que introduzimos primeiramente a constelação do terror, que agora já pode ser citada mais longamente para incluir a interpretação sócio-histórica do jogo pulsional como dominação que procuramos apresentar:

O rigor com que os dominadores impediram no curso dos séculos a seus próprios descendentes bem como às massas dominadas a recaída em modos de vida miméticos -, começando pela proibição de imagens na religião, passando pela proscrição social dos atores e dos ciganos e chegando, enfim, a uma pedagogia que desacostuma

35. DE, p. 156.

36. Não ignoramos o problema sistemático - do ponto de vista da teoria de Freud - que representa a ausência, em "Inibição, sintoma e angústia" (de 1926), da noção de "pulsão de morte" (introduzida em 1920), já que tal noção representa um dos pilares da reformulação que deu origem à chamada "segunda tópica" (1923). Entretanto, também aqui não acreditamos que tal problema sistemático tenha se apresentado enquanto tal para Horkheimer e Adorno em sua leitura de Freud na Dialética do Esclarecimento, de modo que pode ser deixado de lado para os propósitos deste texto.

37. DE, p. 43; DA, p. 55.

38. DE, p. 62 ; DA, p. 81. 
as crianças de serem infantis -, é a própria condição da civilização (Bedingung der Zivilisation). A educação social e individual reforça nos homens seu comportamento objetivante de trabalhadores e impede-os de se perderem nas flutuações da natureza ambiente. Toda diversão, todo abandono tem algo de mimetismo (Mimikry). Foi se enrijecendo contra isso que o eu se forjou. É através de sua constituição que se realiza a passagem da mimese reflexionante para a reflexão dominada (Übergang von reflektorischer Mimesis zu beherrschter Reflexion). Em lugar da assimilação corporal (leibliche Angleichung) à natureza surge a 'recognição no conceito', a apreensão do diverso sob o mesmo. A constelação, porém, na qual a identidade se produz - a identidade imediata da mimese assim como a identidade mediatizada da síntese, a assimilação à coisa no ato cego de viver, assim como a comparação dos objetos reificados na conceitualidade científica - continua a ser a constelação do terror $(\text { Schrecken })^{39}$.

Com essas observações pretendemos apenas indicar que o modelo crítico da Dialética do Esclarecimento parece ser mal compreendido quando entendido como um modelo aporético sem mais. Seu diagnóstico subjacente, que aponta para um bloqueio objetivo da práxis, da ação verdadeiramente transformadora, não pode e não deve ser confundido com ausência de potencial crítico. Muito pelo contrário, a força da Dialética do Esclarecimento está em que, até hoje, permite análises críticas cruciais da vida contemporânea. Não se trata de afirmar que teses cruciais como sobre a indústria cultural ou sobre o nazismo permaneçam plausíveis até hoje em sua formulação de 1947, mas simplesmente de reconhecer que elas são pontos de partida inescapáveis para quem se proponha a estudar tais fenômenos ${ }^{40}$.

39. DE, p. 169; DA, p. 211

40. Dito isso, é preciso lembrar, no entanto, que a linha de análise da psicologia social que sustenta críticas como as formuladas à indústria cultural não continuou a ser desenvolvida com a mesma magnitude nos escritos posteriores de Horkheimer e de Adorno. O primeiro praticamente se absteve de publicar novos textos (embora tenha uma produção significativa, que permaneceu inédita até sua morte). E Adorno dedicou-se mais intensamente, de um lado, a ensaios sobre temas específicos, e, de outro, a escavar os fundamentos da realização da totalidade como totalidade reificada, em sua Dialética negativa, 
Se há, portanto, uma unidade crítica na Dialética do Esclarecimento a ser encontrada para além da contradição performativa e da aporia inerte, essa unidade está, a nosso ver, em uma leitura interessada de Freud que realizaram Horkheimer e Adorno. Isso não significa de maneira alguma, entretanto, ignorar as profundas diferenças entre as constelações conceituais freudianas e as da Dialética do Esclarecimento. Para além da já mencionada diferença de estrutura - Horkheimer e Adorno desenvolvem uma teoria da mimese e não uma teoria das pulsões, o que está longe de ser um problema meramente terminológico -, pode-se pensar em uma série de outras diferenças analíticas relevantes, como o papel de grande destaque concedido ao "terror" quando comparado ao esquema freudiano, o que acarreta arquitetônicas pulsionais bastante diversas. Se Horkheimer e Adorno pretendem responder a problemas de inspiração freudiana, partem também do pressuposto de que a teoria freudiana sozinha não é capaz de respondê-los, ao mesmo tempo em que a tradução das constelações conceituais freudianas em teoria social tem ao final por resultado uma radical transformação desse ponto de partida.

Seja como for, acreditamos que reconstruir as teses fundamentais da Dialética do Esclarecimento a partir de sua base freudiana significará nada menos do que descobrir a chave até hoje oculta de sua urdidura argumentativa e estilística. Se não nos propusemos aqui a realizar essa tarefa em toda a sua amplitude, esperamos pelo menos ter conseguido colocar com clareza os termos desse desafio.

\section{Referências bibliográficas:}

ABROMEIT, J. Max Horkbeimer and the foundations of the Frankfurt School. Cambridge: Cambrige UP, 2011.

ao mesmo tempo em que buscava uma reflexão de cunho mais abrangente sobre a posição da arte no capitalismo tardio, em sua obra póstuma Teoria Estética. É possível que apenas de Marcuse se possa dizer com propriedade que prosseguiu trabalhando no mesmo grau de abstração aberto pela Dialética do Esclarecimento, em seus escritos das décadas de 1950 e 1960. Sobre a apropriação crítica de Freud por Marcuse no livro Eros e civilização, ver CARNAÚBA, M. E. C. Marcuse e a Psicanálise: Teoria Crítica e Teoria Tradicional na gênese do conceito de repressão. Campinas, 152f. Dissertação de Mestrado: IFCH - UNICAMP, 2012. 
ADORNO, T. W./HORKHEIMER, M. Dialética do Esclarecimento. Rio de Janeiro: Jorge Zahar Editor, 1986.

ADORNO, T. W./HORKHEIMER, M. Briefwechsel. Vol. II: 1938-1944. Frankfurt/Main: Suhrkamp, 2004.

BENJAMIN, W. Sobre alguns motivos em Baudelaire. In: Gesammelte Schriften. Vol. I.2. Frankfurt/Main: Suhrkamp, 1972.

CARNAÚBA, M. E. C. Marcuse e a Psicanálise: Teoria Crítica e Teoria Tradicional na gênese do conceito de repressão. Campinas, 152f. Dissertação de Mestrado: IFCH - UNICAMP. 2012.

FREUD, S. Para além do princípio do prazer. In: Gesammelte Werke. Vol. XIII. Frankfurt/Main: Fischer, 1999.

GIANNOTTI, J. A. Origens da dialética do trabalbo. Estudo sobre a lógica do jovem Marx. Porto Alegre: L\&PM, 1985.

HABERMAS, J. Theorie des kommunikativen Handelns. Vol. 1. Frankfurt/Main: Suhrkamp, 1987.

. Der philosopbische Diskurs der Moderne. Frankfurt/Main: Suhrkamp, 1985. 2000

HORKHEIMER, M. Gesammelte Scbriften. Vol. 5. Frankfurt/Main: Fischer, 1987.

LAPLANCHE, J. e PONTALIS J.-B. Vocabulaire de la Psychanalyse. Paris: PUF, 1992.

MARIN, I. L. Psychanalyse et Théorie Critique. Tese de Doutorado. Paris: Université de Paris VII, 2009.

Equilibrio da natureza - equilíbrio na sociedade: configurações todo-parte na filosofia de Jean-Jacques Rousseau. São Paulo. Dissertação de Mestrado. USP. 1999.

NOBRE, M. A dialética negativa de Theodor W. Adorno. A ontologia do estado falso. São Paulo: Iluminuras/FAPESP, 1998.

Lukács e os limites da reificação. Um estudo sobre História e consciência de classe. São Paulo: Editora 34, 2001.

A Teoria Crítica. Rio de Janeiro: Jorge Zahar Editor, 2004. (org.). Curso Livre de Teoria Crítica. Campinas: Papirus, 2008.

NOBRE, M.; REPA, L. (orgs.). Habermas e a reconstrução. Sobre a categoria central da Teoria Crítica babermasiana. Campinas: Papirus, 2012. 